\title{
Rancangan Program Aplikasi Al-Faraidh sebagai Media Pembelajaran Mawaris di MAN Model Banda Aceh
}

\author{
Amru Sujud ${ }^{1}$, Juanda BJ ${ }^{2}$, Sandy Vrianda ${ }^{3}$ \\ ${ }^{1}$ MAN Model Banda Aceh \\ 2 MAN Model Banda Aceb \\ 3 MAN Model Banda Aceh
}

\section{article info}

\section{Article history:}

Received 28 December 2016

Received in revised form

26 Maret 2017

Accepted 27 Maret 2017

Available online 7 April 2017

\section{Keynords:}

Applications

Alfaraidh,

Mawaris, Media

Learning
Kata Kunci:

Aplikasi Alfaraidh,

Mawaris, Media

Pembelajaran a b s tract

This study aims to design a new system and method of application program Al-Faraidh as a medium of learning fiqih mawaris in MAN Model Banda Aceh. This research uses qualitative descriptive method, that is by collecting data through interview with fiqih teachers and literature study. The study of jurisprudence is difficult to achieve the expected competence, mawaris calculation is also still done manually. Students tend to be less interested in learning fiqih mawaris because it is considered too difficult. Therefore it is necessary to design an application program as a learning medium that facilitates and attracts students' attention. The design of the web-based application program can process the data muwaris (person who left the heirs), data of heirs along with his position against muwaris, heirs, muwaris reports, and recapitals report on the division of inheritance. The application program is expected to be an effective solution of the problem, thus simplifying the process of calculating the inheritance, especially in the process of learning.

\section{$\mathrm{abstrak}$}

Penelitian ini bertujuan merancang sebuah sistem dan metode baru berupa program aplikasi Al-Faraidh sebagai media pembelajaran fiqih mawaris di MAN Model Banda Aceh. Penelitian ini menggunakan metode deskriptif kualitatif, yaitu dengan mengumpulkan data melalui wawancara dengan Guru Fiqih dan studi pustaka. Pembelajaran fiqih mawaris sulit mencapai kompetensi yang diharapkan, perhitungan mawarisnya juga masih dilakukan secara manual. Siswa cenderung kurang tertarik mempelajari fiqih mawaris karena dianggap terlalu sulit. Oleh karena itu diperlukan sebuah rancangan program aplikasi sebagai media pembelajaran yang memudahkan dan menarik perhatian siswa. Rancangan program aplikasi yang berbasis web tersebut dapat mengolah data muwaris (orang yang meninggalkan harta waris), data ahli waris beserta kedudukannya terhadap muwaris, harta waris, laporan muwaris, dan laporan rekap hasil pembagian harta waris. Program aplikasi tersebut diharapkan dapat menjadi solusi yang efektif dari permasalahan tersebut, sehingga mempermudah proses perhitungan harta waris, khususnya dalam proses pembelajaran. 


\section{Latar Belakang}

Seiring dengan perkembangan teknologi informasi yang sangat pesat kini telah menghadirkan perubahan yang sangat signifikan. Dengan hadirnya teknologi informasi, segala aspek kehidupan berubah sangat drastis. Teknologi informasi dapat membantu kehidupan manusia menjadi lebih mudah dan efisien melalui berbagai macam aplikasi yang ada, baik dalam dunia kerja, instansi perkantoran maupun dunia pendidikan. Penerapan teknologi informasi telah diaplikasikan dalam seluruh aspek pembelajaran di MAN Model Banda Aceh Salah satu pengembangan aplikasi teknologi informasi diterapkan dalam pembelajaran fiqih mawaris.

Mawaris adalah ilmu fiqih yang bertujuan untuk mengetahui orang-orang yang berhak menerima warisan, orang-orang yang tidak berhak menerimanya, bagian masing-masing ahli waris dan cara pembagiannya (Zainuddin, 2008:102). Sebuah hadis menyatakan pentingnya belajar ilmu mawaris, (Al-Albani, 2008) "Wahai Abu Hurairah, belajarlah faraidh (ilmu waris) dan ajarkanlah, karena sesungguhnya ia adalah setengah dari ilmu, dan ilmu itu akan dilupakan dan ia adalah yang pertama kali dicabut dari umatku" (HR. Ibnu Majah, Ad Daruquthni, Al Hakim, Al Baihaqi).

Pembelajaran fiqih mawaris selama ini sulit mencapai kompetensi yang diharapkan karena perhitungan mawaris yang dilakukan secara manual. Siswa cenderung kurang tertarik mempelajari fiqih mawaris karena dianggap terlalu sulit. Oleh karena itu diperlukan sebuah rancangan program aplikasi sebagai media pembelajaran yang memudahkan dan menarik perhatian siswa dalam mempelajari fiqih mawaris.

MAN Model Banda Aceh merupakan salah satu madrasah favorit yang ada di provinsi Aceh. Dalam pengembangan pembelajarannya telah mengkombinasikan konsep pembelajaran sains berbasis nilai-nilai ilmu agama. Pengembangan ilmu pengetahuan dan teknologi (IPTEK) telah berjalan selaras dengan pengembangan pembelajaran pendidikan agama islam. Seluruh kegiatan administrasi pembelajaran sudah dilakukakan dengan sistem informasi madrasah.

Seiring dengan perkembangan teknologi informasi yang sangat pesat kini telah menghadirkan perubahan yang sangat signifikan. Dengan hadirnya teknologi informasi, segala aspek kehidupan berubah sangat drastis. Teknologi informasi dapat membantu kehidupan manusia menjadi lebih mudah dan efisien melalui berbagai macam aplikasi yang ada, baik dalam dunia kerja, instansi perkantoran maupun dunia pendidikan. Penerapan teknologi informasi telah diaplikasikan dalam seluruh aspek pembelajaran di MAN Model Banda Aceh. Salah satu pengembangan aplikasi teknologi informasi diterapkan dalam pembelajaran fiqih mawaris.

Mawaris adalah ilmu fiqih yang bertujuan untuk mengetahui orang-orang yang berhak menerima warisan, orang-orang yang tidak berhak menerimanya, bagian masing-masing ahli waris dan cara pembagiannya (Zainuddin, 2008:102). Sebuah hadis menyatakan pentingnya belajar ilmu mawaris, (Al-Albani, 2008) "Wahai Abu Hurairah, belajarlah faraidh (ilmu waris) dan ajarkanlah, karena sesungguhnya ia adalah setengah dari ilmu, dan ilmu itu akan dilupakan dan ia adalah yang pertama kali dicabut dari umatku" (HR. Ibnu Majah, Ad Daruquthni, Al Hakim, Al Baihaqi).

Pembelajaran fiqih mawaris selama ini sulit mencapai kompetensi yang diharapkan karena perhitungan mawaris yang dilakukan secara manual. Siswa cenderung kurang tertarik mempelajari fiqih mawaris karena dianggap terlalu sulit. Oleh karena itu diperlukan sebuah rancangan program aplikasi sebagai media pembelajaran yang memudahkan dan menarik perhatian siswa dalam mempelajari fiqih mawaris.

\section{Metode Penelitian}

\subsection{Desain Penelirian}

Penelitian ini menggunakan metode penelitian kualitatif bersifat deskriptif atau descriptive research. Suryabrata (2012:75) menjelaskan bahwa, "Secara harfiah, penelitian deskriptif adalah penelitian yang bertujuan untuk membuat pencandraan secara sistematis, faktual dan akurat mengenai fakta-fakta dan sifat-sifat populasi pada daerah tertentu". Data yang dikumpulkan dalam penelitian deskriptif adalah berupa kata-kata, gambar, dan bukan angka- 
angka. Hal ini disebabkan oleh adanya penerapan metode kualitatif. Dengan demikian, laporan penelitian ini akan berisi kutipan-kutipan data untuk memberi gambaran penyajian laporan tersebut. Data tersebut mungkin berasal dari naskah wawancara, catatan lapangan, foto, videotape, dokumen pribadi, catatan atau memo, dan dokumen resmi lainnya. (Moleong, 2006).

Penelitian kualitatif bersifat deskriptif artinya hasil eksplorasi atas subjek penelitian atau para partisipan melalui pengamatan dengan semua variannya, dan wawancara mendalam serta Focus Groups Discussion (FGD) harus dideskripsikan dalam catatan kualitatif yang terdiri dari catatan lapangan, catatan wawancara, catatan pribadi, catatan metodologis, dan catatan teoretis. (Putra, 2012:71). Deskripsi mengharuskan peneliti menggambarkan secara rinci, lengkap dan mendalam hasil wawancara, pengamatan dan FGD. FGD adalah diskusi yang dilakukan dalam kelompok dengan topik-topik tertentu yang dapat membantu memperdalam sekaligus memeriksa data.

Berdasarkan pendapat di atas, maka penelitian kualitatif bersifat deskriptif yang dimaksud dalam penelitian ini adalah suatu metode penelitian yang menganalisis dan memecahkan masalah berdasarkan penelitian di lapangan dan beberapa sumber data yang berkaitan dengan topik pembahasan. Kemudian mendeskripsikan dan menjelaskan fenomena hasil temuan di lapangan secara sistematis dan akurat.

\subsection{Sumber dan Teknik Pengumpulan Data}

Sumber dan teknik pengumpulan data merupakan bagian integral dari desain penelitian. Tersedia berbagai teknik pengumpulan data dengan segala kelebihan dan kekurangannya. Secara garis besar sumber dan teknik pengumpulan data yang peneliti gunakan sebagai berikut :

\section{a. Sumber Data Primer}

Menurut Sarwono (2006:209) definisi data primer adalah data yang diperoleh melalui pertanyaan tertulis dengan menggunakan kuesioner atau lisan dengan metode wawancara.

b. Sumber Data Sekunder

Menurut Sarwono (2006:209) definisi data sekunder adalah data yang bukan dari sumber pertama sebagai sarana untuk memperoleh data atau informasi untuk menjawab masalah yang diteliti. Data Sekunder yang diperoleh peneliti berdasarkan dokumentasi-dokumentasi dari beberapa buku, seperti "Kupas Tuntas Adobe Dreamweaver dengan Pemrograman PHP \& MySQL" karangan Madcoms dan "Pemrograman Database MySQL untuk Pemula" karangan Abdul Kadir.

\subsection{Teknik Pengumpulan Data}

a. Observasi

Observasi adalah pengamatan secara langsung ke lapangan untuk melihat lebih dekat objek yang akan diteliti. Observasi menurut Patton adalah "Deskripsi kerja lapangan kegiatan, perilaku, tindakan, percakapan, interaksi interpersonal, organisasi atau proses masyarakat, atau aspek lain dari pengalaman manusia yang dapat diamati. Data terdiri dari catatan lapangan, melalui deskripsi rinci termasuk konteks dimana pengamatan dilakukan" (Emzir, 2012:65). Jenis observasi yang dilakukan dalam penelitian ini adalah observasi non partisipan.

b. Wawancara

Wawancara merupakan salah satu teknik pengumpulan data dengan melakukan tanya jawab bersama narasumber. Wawancara ini dilakukan apabila ingin mendapat informasi lebih mendalam tentang sesuatu yang akan diteliti. Menurut Patton wawancara adalah "Pertanyaaan terbuka dan teliti hasil tanggapan mendalam tentang pengalaman, persepsi, pendapat, perasaan, dan pengetahuan orang. Data terdiri dari kutipan yang sama persis dengan konteks yang cukup untuk dapat diinterpretasi”. (Emzir, 2012:65). Yang menjadi sasaran wawancara dalam penelitian ini adalah Guru Fiqih dan Guru Teknologi Informasi dan Komunikasi di MAN Model Banda Aceh.

\subsection{Kebutuhan Perangkat Lunak}

Proses pengumpulan kebutuhan diintensifkan dan difokuskan pada perangkat lunak. Untuk memahami sifat program yang dibangun, perekayasa perangkat lunak (analisis) harus memahami domain informasi, tingkah laku untuk kerja, dan antarmuka (interface) yang diperlukan. Dalam merancang suatu perangkat lunak, perlu memperhatikan kebutuhan yang akan digunakan dalam perancangan aplikasi sebagai berikut : 
a. Hardware

Spesifikasi kebutuhan perangkat keras dalam penelitian ini adalah sebagai berikut :

- Laptop/PC

- Processor minimum Intel Pentium IV

- RAM minimum $512 \mathrm{MB}$

b. Software

Spesifikasi kebutuhan perangkat lunak dalam penelitian ini adalah sebagai berikut :

- Sebagai web browser seperti; Internet Explorer, Mozilla Firefox, Google Chrome.

- PHP, sebagai bahasa pemrograman untuk membuat perangkat lunak.

- Adobe Dreamweaver, sebagai aplikasi perancangan antarmuka web.

- MySQL, sebagai software database.

- Xampp, sebagai web server

\subsection{Entity Relational Diagram}

Menurut Fathansyah (2012:79) Entity Relationship Diagram (ERD) merupakan model yang berisi komponen-komponen Himpunan Entitas dan Himpunan Relasi yang masing-masing dilengkapi dengan atribut-atribut yang merepresentasikan seluruh fakta dari 'dunia nyata'. Notasi-notasi simbolik di dalam Diagram E-R yang dapat digunakan adalah :

a. Persegi panjang, menyatakan impunan Entitas

b. Lingkaran/ elipse, menyatakan Atribut

c. Belah ketupat, menyatakan Himpunan Relasi

d. Garis, sebagai penghubung antara Himpunan Relasi dengan Himpunan Entitas dan Himpunan Entitas dengan Atributnya.

e. Kardinalitas dapat dinyatakan dengan banyaknya garis cabang atau dengan pemakaian angka.

Berikut adalah ERD dari perancangan program aplikasi Al Faraidh v1.0:

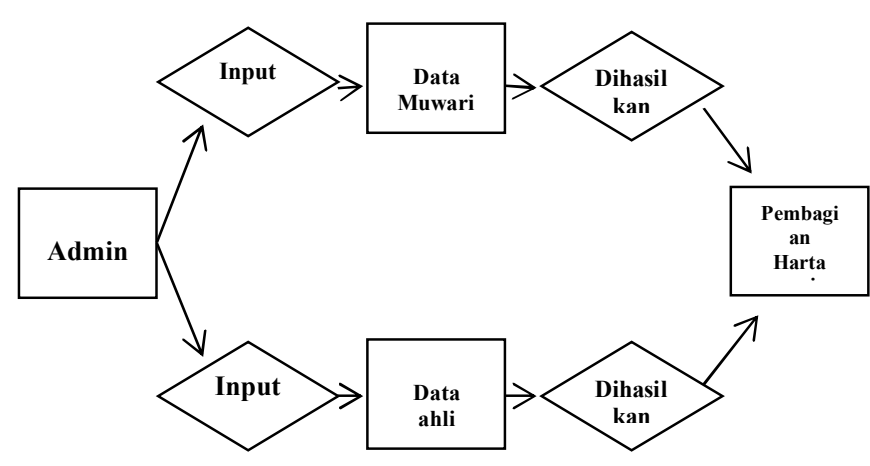

Gambar 1. Entity Relationship Diagram (ERD)

2.6.Rancangan Aplikasi

Halaman Input Muwaris

Menu input muwaris merupakan halaman dimana user dapat menginput data-data muwaris.

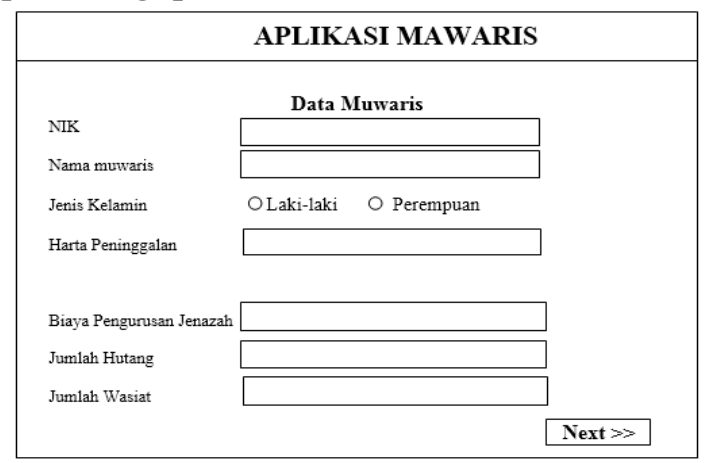

Gambar 2. Halaman Input Data Muwaris

Adapun cara meng-input data muwaris adalah dengan mengisi nama muwaris, memilih jenis kelamin, mengisi harta peninggalan, biaya pengurusan jenazah, jumlah hutang, dan jumlah wasiat. Kemudian klik hitung untuk menghasilkan jumlah harta bersih yang diwariskan dan akan dilanjutkan ke langkah selanjutnya secara otomatis.

Halaman Input Ahli Waris

Menu input ahli waris merupakan halaman dimana user dapat menginput data ahli waris. Adapun rancangan aplikasinya adalah sebagai berikut:

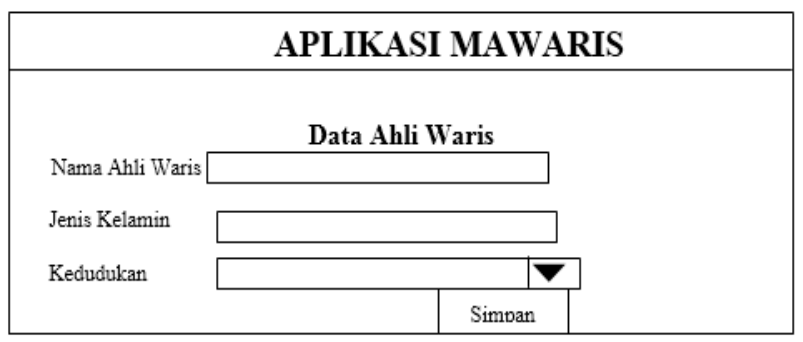

Gambar 3. Halaman input data ahli waris 
Adapun cara meng-input data ahli waris dengan memasukkan nama ahli waris, pilih ahli waris, dan tentukan kedudukan ahli waris tersebut, klik tanda tambah untuk menambah ahli waris selanjutnya, kemudian akan terlihat data ahli waris yang telah di tambahkan. Klik Next untuk melihat hasil pembagian.

\section{Halaman Laporan}

Menu halaman hasil merupakan halaman dimana user dapat melihat hasil pembagian harta waris.

\begin{tabular}{||l|l|l|l|}
\hline \multicolumn{5}{|c|}{ APLIKASI MAWARIS } \\
\hline \multicolumn{4}{|c|}{ Laporan Data Ahli Waris (Nama Muwaris) } \\
\hline \multicolumn{5}{|c|}{} \\
\hline No. & \multicolumn{1}{|c|}{ Nama } & Kedudukan & Jumlah \\
\hline 1 & $\mathrm{xxxx}$ & $\mathrm{xxxx}$ & $\mathrm{xxxxxxxxx}$ \\
\hline 2 & $\mathrm{xxxx}$ & $\mathrm{xxxx}$ & $\mathrm{xxxxxxxx}$ \\
\hline 3 & $\mathrm{xxxx}$ & $\mathrm{xxxx}$ & $\mathrm{xxxxxxxx}$ \\
\hline 4 & $\mathrm{xxxx}$ & $\mathrm{xxxx}$ & $\mathrm{xxxxxxxx}$ \\
\hline \multicolumn{5}{|c|}{} \\
\hline
\end{tabular}

Gambar 4. Halaman Laporan Data Mawaris

\section{Pembahasan}

a. Mawaris dan Penggolongan Ahli Waris

Dari segi istilah mawaris atau ilmu faraidh adalah ilmu untuk mengetahui orang-orang yang berhak menerima warisan, orang-orang yang tidak berhak menerimanya, bagian masing-masing ahli waris dan cara pembagiannya. Ahli Waris ialah orang yang berhak menerima warisan, ditinjau jenisnya dapat dibagi dua, yaitu zawil furud dan ashabah.

Penggolongan ahli waris dibagi menjadi dua jenis yaitu laki-laki dan perempuan (Zainuddin, 2008:108).

\section{Ahli Waris Laki-laki}

Adapun daftar ahli waris laki-laki adalah sebagai berikut:

\section{a. Anak laki-laki}

b. Cucu laki-laki sampai kebawah dari garis anak laki-laki.

c. Ayah

d. Kakek sampai keatas garis ayah

e. Saudara laki-laki kandung

f. Saudara laki-laki seayah

g. Saudara laki-laki seibu

h. Anak laki-laki saudara kandung sampai kebawah. i. Anak laki-laki saudara seayah sampai kebawah.

j. Paman kandung

k. Paman seayah

1. Anak paman kandung sampai kebawah.

m. Anak paman seayah sampai kebawah.

n. Suami

o. Laki-laki yang memerdekakan budak

\section{Ahli Waris Perempuan}

Adapun daftar ahli waris laki-laki adalah sebagai berikut:
a. Anak perempuan
b. Cucu perempuan sampai kebawah dari anak laki-laki.
c. Ibu
d. Nenek sampai keatas dari garis ibu
e. Nenek sampai keatas dari garis ayah
f. Saudara perempuan kandung
g. Saudara perempuan seayah
h. Saudara perempuan seibu
i. Istri
j. Wanita yang memerdekakan budak

\section{b. Sudut Pembagian Harta (Furudh Muqaddarah)}

Ditinjau dari sudut pembagian ahli waris terbagi dua (Zainuddin, 2008:110):

\section{Ashabul furudh}

Ashabul furudh yaitu orang yang mendapat bagian tertentu, yaitu::

a. Yang mendapat bagian 1/2 harta.

1) Anak perempuan kalau sendiri

2) Cucu perempuan kalau sendiri

3) Saudara perempuan kandung kalau sendiri

4) Saudara perempuan seayah kalau sendiri

5) Suami

b. Yang mendapat bagian 1/4 harta.

1) Suami dengan anak atau cucu

2) Istri atau beberapa kalau tidak ada (anak atau cucu)

c. Yang mendapat bagian 1/8 harta.

1) Istri atau beberapa isteri dengan anak atau cucu.

d. Yang mendapat 2/3 harta.

1) Dua anak perempuan atau lebih

2) Dua cucu perempuan atau lebih

3) Dua saudara perempuan kandung atau lebih

4) Dua saudara perempuan seayah atau lebih

e. Yang mendapat 1/3 harta. 
1) Ibu jika tidak ada anak, cucu dari garis anak laki-laki, dua saudarakandung/seayah atau seibu.

2) Dua atau lebih anak ibu baik laki-laki atau perempuan

f. Yang mendapat $1 / 6$ harta.

1) Ibu bersama anak laki-laki, cucu laki-laki atau dua atau lebih saudara perempuan kandung atau perempuan seibu.

2) Nenek garis ibu jika tidak ada ibu dan terus keatas

3) Nenek garis ayah jika tidak ada ibu dan ayah terus keatas

4) Satu atau lebih cucu perempuan dari anak laki-laki bersama satu anak perempuan kandung

5) Satu atau lebih saudara perempuan seayah bersama satu saudara perempuan kandung.

6) Ayah bersama anak laki-laki atau cucu laki-laki

7) Kakek jika tidak ada ayah

8) Saudara seibu satu orang, baik laki-laki atau perempuan.

2. Ahli waris ashabah

Ahli waris ashabah adalah para ahli waris tidak mendapat bagian tertentu tetapi mereka dapat menghabiskan bagian sisa ashhabul furud. Ashabah terbagi tiga jenis yaitu ashabah binafsibi, ashabah bighairi dan ashabah menghabiskan bagian tertentu.

a. Ashabah binafsibi adalah yang ashabah dengan sendirinya. Tertib ashabah binafsibi sebagai berikut:

1) Anak laki-laki

2) Cucu laki-laki dari anak laki-laki terus kebawah

3) Ayah

4) Kakek dari garis ayah keatas

5) Saudara laki-laki kandung

6) Saudara laki-laki seayah

7) Anak laki-laki saudara laki-laki kandung sampai kebawah

8) Anak laki-laki saudara laki-laki seayah sampai kebawah

9) Paman kandung

10) Paman seayah

11) Anak laki-laki paman kandung sampai kebawah

12) Anak laki-laki paman seayah sampai kebawah
13) Laki-laki yang memerdekakan yang meninggal

b. Ashabah dengan dengan saudaranya

1) Anak perempuan bersama anak laki-laki atau cucu laki.

2) Cucu perempuan bersama cucu laki-laki

3) Saudara perempkuan kandung bersama saudara laki-laki kandung atau saudara laki-laki seayah.

4) Saudara perempuan seayah bersama saudara laki-laki seayah.

c. Ashabah Menghabiskan bagian tertentu

1) Anak perempuan kandung satu orang bersama cucu perempuan satu atau lebih $(2 / 3)$.

2) Saudara perempuan kandung bersama saudara perempuan seayah $(2 / 3)$

c. Implementasi Program

Dari penelitian yang telah dilakukan, dihasilkan suatu sistem pembelajaran baru mengenai mawaris dalam pembelejaran. Pada aplikasi ini menampilkan informasi, materi, soal-soal latihan dan simulasi penghitungan mawaris. Pada menu materi terdapat materi mawaris, contoh-contoh soal mawaris, dan simulasi penghitungan harta warisan.

1. Halaman Awal

Menu Halaman Awal merupakan halaman depan aplikasi. Pada menu ini, terdapat nama aplikasi yaitu Aplikasi Al-Faraidh v1.0, logo Organisasi Siswa Intra Madrasah (OSIM) MAN Model Banda Aceh, dan ayat perintah untuk mewajibkan mewariskan harta peninggalan. Kemudian terdapat 3 link, yaitu:

1. Materi, untuk menuju halaman materi tentang mawaris.

2. Contoh Kasus, untuk menuju halaman contoh kasus atau soal.

3. Hitung, untuk menuju halaman penghitungan harta warisan. 


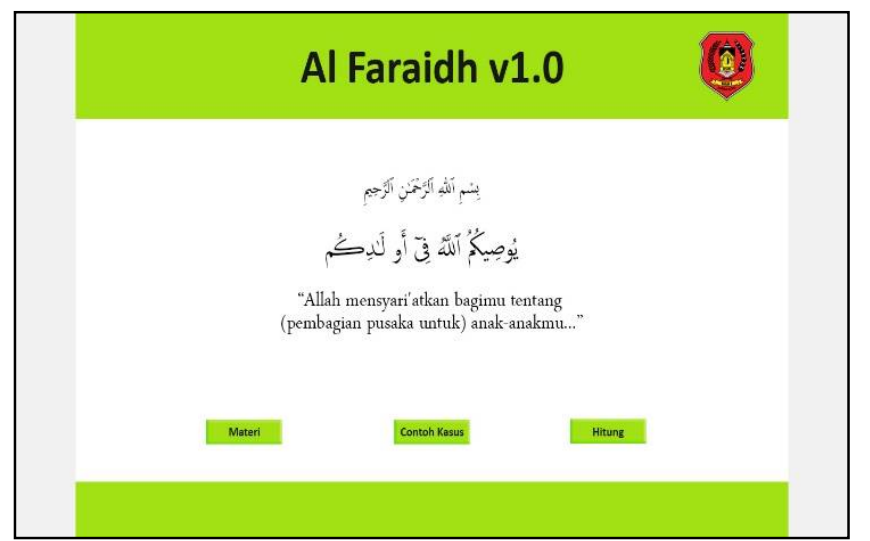

Gambar 5. Halaman awal

2. Halaman Materi

Halaman Materi merupakan halaman yang berisi materi tentang mawaris. Menu materi dapat dilihat pada gambar 6 .

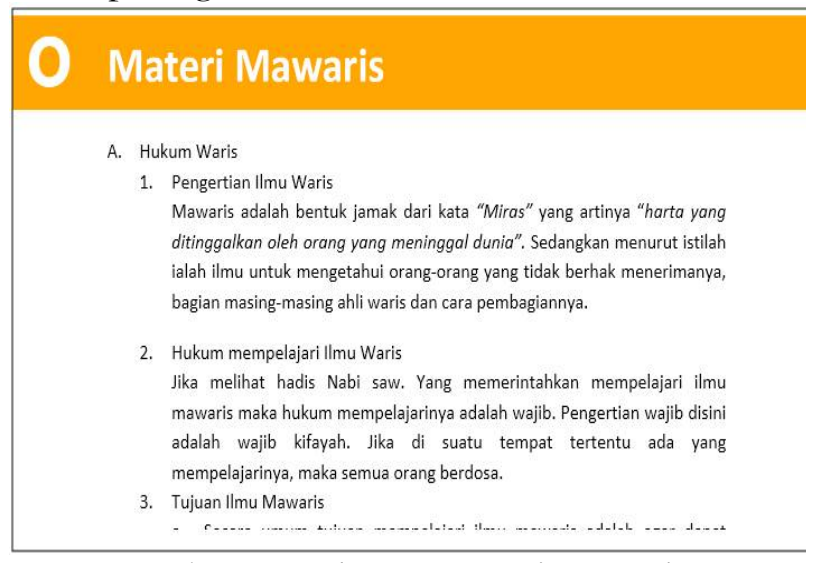

Gambar 6. Halaman materi mawaris

\section{Halaman Contoh Soal}

Halaman Contoh Soal merupakan halaman yang berisi materi tentang soal-soal dan kasus pembagian harta warisan mawaris. Menu contoh soal dapat dilihat pada gambar 7 .

\section{Contoh Soal/Kasus}

Soal 1. Jika (C)suami meninggal dunia, siapa sajakah ahli warisnya, dan berapakah bagiannya ?

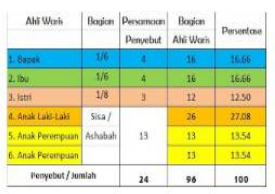

Penjelasan:

-Sisa 13 harus dibagi rata menjadi 4 ( 2 bagian untuk anak perempuan +2 bagian untuk seorang anak laki-laki).

-Kalau tidak bulat hasilnya, kalikan saja $13 \times 4$, kalikan juga hasil bagian ahli waris lain dan

Gambar 7. Halaman contoh soal/kasus

Menu contoh soal akan menampilkan soal-soal yang berkaitan dengan mawaris. Pada menu ini juga ditampilkan pembahsan-pembahasan terhadap contoh soal yang ada.

4. Halaman Data Muwaris

Menu Data Munaris merupakan halaman dimana user dapat menginput data-data muwaris atau orang yang mendapatkan harta warisan. Data yang harus dimasukkan adalah NIK (Nomor Induk Kependudukan), Nama Muwaris, Jenis Kelamin, Harta Peninggalan, Biaya Urus Jenazah, Jumlah Hutang, dan Jumlah Wasiat. Menu Data Muwaris dapat dilihat pada gambar 8 .

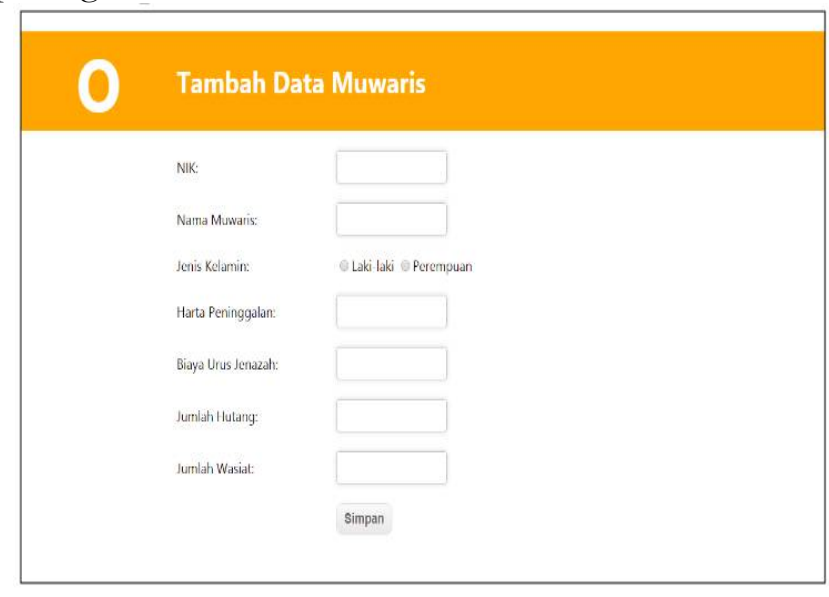

Gambar 8. Halaman tambah data muwaris

Berikut adalah keterangan dan cara memasukkan data muwaris:

- NIK, masukkan nomor KTP muwaris.

- Nama Muwaris, masukkan nama muwaris.

- Jenis Kelamin, pilih salah satu jenis kelamin muwaris.

- Harta Peninggalan, masukkan harta yang ditinggalkan oleh muwaris.

- Biaya Urus Jenazah, masukkan jumlah biaya pengurusan jenazah muwaris.

- Jumlah Hutang, masukkan jumlah hutang yang ditinggalkan oleh muwaris.

- Jumlab Wasiat, masukkan jumlah harta yang diwasiatkan oleh muwaris maksimal $1 / 3$ harta warisan.

- Simpan, untuk menyimpan data dan melanjutkan ke halaman selanjutnya.

5. Halaman Input Ahli Waris

Menu Input Abli Waris merupakan halaman dimana user dapat menginput data ahli waris. Data yang harus dimasukkan adalah Nama Ahli Waris, Jenis Kelamin, dan Kedudukan-nya terhadap 
muwaris. Menu input ahli waris dapat dilihat pada gambar 9 .

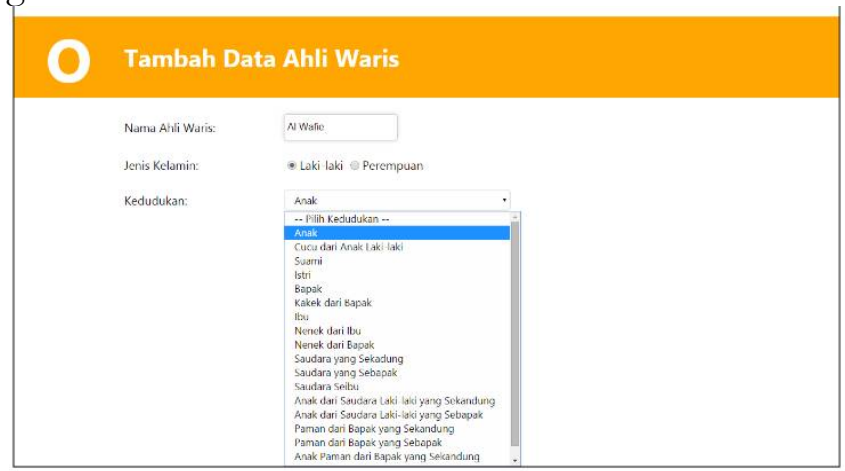

Gambar 9. Halaman tambah data ahli waris

Berikut adalah keterangan dan cara memasukkan data muwaris:

- Nama Abli Waris, masukkan nama ahli waris muwaris.

- Jenis Kelamin, pilih salah satu jenis kelamin ahli waris.

- Kedudukan, pilih salah satu kedudukan ahli waris terhadap muwaris.

\section{Halaman Laporan Data Ahli Waris}

Menu Laporan Data Abli Waris merupakan halaman hasil pembagian harta waris. Pada menu ini akan dimunculkan data-data ahli waris, kedudukannya, dan jumlah bagian hartanya.

\begin{tabular}{|c|c|c|c|}
\hline \multicolumn{3}{|c|}{ Laporan Data Ahli Waris (Sandi Frianda) -- Rp 115000000} & + \\
\hline 26 Amru Sujud & Anak & Laki-laki & Hapus \\
\hline 27 Juanda BJ & Suami & Lakk-aki & Hapus \\
\hline 28 Shallihah & Saudara yang Sebapak & Perempuan & Hapus \\
\hline 29 Ahmad Muhadin & Bapak & Lakk-laki & Hapus \\
\hline 30 Cut Januarita & Ibu & Perempuan & Hapus \\
\hline 31 Al Wafie & Paman dari Bapak yang Sebapak & Laki-laki & Hapus \\
\hline $32 \mathrm{M} . \mathrm{Irtan}$ & Anak & Laki-laki & Hapus \\
\hline
\end{tabular}

Gambar 10. Halaman tambah data ahli waris

7. List Data Muwaris

Menu List Data Muwaris merupakan halaman data-data ahli waris yang tersimpan di database. Pada menu ini akan ditampilkan banyaknya data-data muwaris dan laporannya.

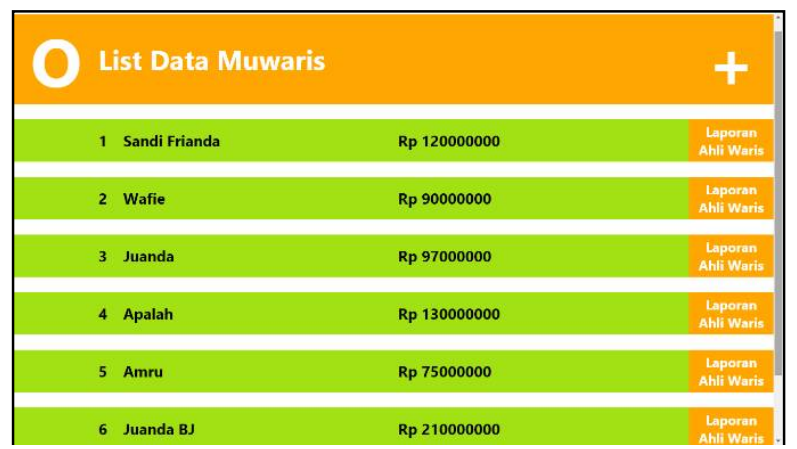

Gambar 11. Halaman list data munaris

\section{Kesimpulan dan Saran}

Berdasarkan hasil pengamatan dan analisa yang telah dilakukan, maka dapat ditarik kesimpulan sebagai berikut :

1. Rancangan program aplikasi Al Faraidh v1.0 menggunakan PHP dan MySQL ini bertujuan untuk memperkenalkan salah satu sistem media pembelajaran teknologi informasi yang baru pada sistem pembelajaran mawaris di MAN Model Banda Aceh, dengan tidak mengabaikan sistem pembelajaran yang telah ada sebelumnya.

2. Dengan adanya media pembelajaran seperti ini, diharapkan semua penggunanya dapat dengan mudah dan cepat mempelajari ilmu mawaris.

\section{Daftar Pustaka}

Al-Albani, M.N., 2008. Shahih Sunan Ibnu Majah, terj. Ahmad Taufiq Abdurahman, Jilid II. Jakarta: Pustaka Azzam.

Emzir, M. and Pd, M., 2012. Metodologi Penelitian Kualitatif Analisis data. Jakarta: Raja Grafindo.

Fathansyah, I., 2012. Basis Data edisi: revisi. Bandung: CV. Infomatika.

Jonathan, S., 2006. Metode Penelitian Kuantitatif dan Kualitatif. Yogyakarta: Graha Ilmu.

Moleong, L.J., 2006. Metodologi Penelitian Kualitatif Edisi Revisi, Cetakan keduapuluh dua, Bandung: PT. Remaja Rosdakarya Offset.

Putra, N., 2012. Metode Penelitian Kualitatif Pendidikan. Jakarta: Rajawali Pers. 
Suryabrata, S., 2012. Metodologi Penelitian, Jakarta, Penerbit PT. Rajagrafindo Persada.

Zainuddin, Djedjen, dkk. 2008. Pendidikan Agama Islam Fiqih. Jakarta: PT. Karya Toha Putra. 